\title{
Phytochrome B1-dependent control of SP5G transcription is the basis of the night break and red to far-red light ratio effects in tomato flowering
}

\author{
Kai Cao ${ }^{1,3,4}$, Fei Yan², Dawei Xu ${ }^{1,3}$, Kaiqi $\mathrm{Ai}^{3}$, Jie Yu ${ }^{3}$, Encai Bao ${ }^{1,3,4}$ and Zhirong Zou ${ }^{1,3^{*}}$ (1)
}

\begin{abstract}
Background: Phytochromes are dimeric proteins with critical roles in perceiving day length and the environmental signals that trigger flowering. Night break (NB) and the red to far-red light ratio (R:FR) have been used extensively as tools to study the photoperiodic control of flowering. However, at the molecular level, little is known about the effect of NB and different R:FR values on flowering in day-neutral plants (DNPS) such as tomato.

Results: Here, we show that tomato SP5G, SP5G2, and SP5G3 are homologs of Arabidopsis thaliana FLOWERING LOCUS T (FT) that repress flowering in Nicotiana benthamiana. NB every $2 \mathrm{~h}$ at intensities of $10 \mu \mathrm{mol} \mathrm{m} \mathrm{m}^{-2} \mathrm{~s}^{-1}$ or lower R:FR (e.g., 0.6) caused a clear delay in tomato flowering and promoted SP5G mRNA expression. The promoted SP5G mRNA expression induced by red light NB and low R:FR treatments was reversed by a subsequent FR light stimulus or a higher R:FR treatment. The tomato phyB1 mutation abolished the effects of NB and lower R:FR treatments on flowering and SP5G mRNA expression, indicating that the effects were mediated by phytochrome B1 in tomato.
\end{abstract}

Conclusion: Our results strongly suggest that SP5G mRNA suppression is the principal cause of NB and lower R:FR effects on flowering in tomato.

Keywords: Tomato, Red to far-red light ratio, Night break, Phytochrome B1, Flowering, SP5G

\section{Background}

Plants are sessile organisms that cannot therefore migrate from a suboptimal environment to a more favorable one. Thus, they have developed mechanisms that allow them to alter their growth and development in response to environmental signals, thereby increasing their likelihood of survival and reproductive success. The transition from the vegetative phase to the reproductive phase is a particularly well-studied example of how the external environment regulates plant development. Photoperiod is one of the most important regulators of flowering for successful reproduction [1]. Flowering

\footnotetext{
*Correspondence: zouzhirong2005@hotmail.com

${ }^{1}$ The Agriculture Ministry Key Laboratory of Agricultural Engineering in the Middle and Lower Reaches of Yangze River, Jiangsu Academy of Agricultural Sciences, Nanjing, China

${ }^{3}$ Horticulture College, Northwest A\&F University, Yangling, Shaanxi, China Full list of author information is available at the end of the article
}

plants can be divided into three groups according to their responses to photoperiod: long-day plants (LDPs), which flower faster under long-day (LD) conditions; short-day plants (SDPs), which are stimulated to flower under short-day (SD) conditions; and day-neutral plants (DNPs), which flower in a manner that is insensitive to the photoperiod.

In the LDP Arabidopsis thaliana, the expression of the CONSTANS (CO) is regulated by the circadian clock and subsequently induces FLOWERING LCOUS T (FT) expression when exposed to LD conditions $[2,3]$. The genome of the SDP rice contains Heading date $1(H d 1)$ and Heading date $3 a(\mathrm{Hd} 3 a)$, homologs of Arabidopsis CO and $F T$ that play important roles in the regulation of flowering $[4,5]$. $H d 1$ actives $H d 3 a$ expression under inductive SD conditions, whereas $H d 1$ suppresses $H d 3 a$ under non-inductive LD conditions. The DNP tomato

(c) The Author(s). 2018 Open Access This article is distributed under the terms of the Creative Commons Attribution 4.0 International License (http://creativecommons.org/licenses/by/4.0/), which permits unrestricted use, distribution, and 
expresses four FT-like proteins (SP3D, SP5G, SP5G2, SP5G3). SFT/SP3D is a floral activator, and its expression is not altered by photoperiod [6]. SP5G is a floral repressor, and it is expressed at higher levels under LD conditions relative to SD conditions, which promote tomato flowering slightly earlier under SD conditions [6]. FT-like proteins that influence plant flowering have also been identified in dicotyledonous plants such as poplar $[7,8]$, apple [9], sugar beet [10], pumpkin [11], sunflower [12], pea [13], soybean [14], and potato [15], as well as monocotyledonous plants such as rice [16], wheat [17] and maize [18].

The night break (NB) effect on flowering has been discovered in both LDPs [19] and SDPs [20]. In Arabidopsis, a 1-h exposure to light given every day in the middle of the night can result in early flowering [19]. The NB effect on flowering is most evident in SDPs, in which flowering is inhibited by a very short exposure of light during the night. In rice, a 10-min NB had clear effects on flowering when applied for various numbers of days [20]. Early studies in rice on the light quality required for NB indicated that red (R) light is most effectively induces this response.

Phytochrome B is the major photoreceptor used for $\mathrm{NB}$, which causes delayed flowering by suppressing the expression of $H d 3 a$ [20, 21]. In Pharbitis, another SDP, NB suppressed the expression of PnFT1 and PnFT2, which are orthologs of Arabidopsis FT that induce late flowering [22]. The effect of NB on the flowering of DNPs has been investigated in few plants such as Geranium [23]. In addition to the duration of the light period, light quality (wavelength) is another one of the most important ambient signal for plants flowering. Plants growing under a canopy experience lower red (R) to far-red (FR) ratios (R:FR) than plants growing in full sun, because leaves absorb more $\mathrm{R}$ light than FR light. Low R:FR values are perceived by the phytochrome family of proteins and induce a range of responses including stem and petiole elongation, hyponastic leaves, reduced branching, and early flowering [1, 24]. For many species, FR-enriched light is known to influence plant flowering, but the molecular details are unknown. In Arabidopsis, FR-enriched light can increase $\mathrm{CO}$ protein levels independent of transcription and promote the expression of $F T[25,26]$.

Plants are able to respond properly to environmental changes because they have evolved multiple photoreceptor systems that utilize phytochromes, cryptochromes, and phototropins, which perceive light signals over a broad range of wavelengths and intensities. Phytochromes mainly perceive $\mathrm{R}$ and FR light, while cryptochromes and phototropins recognize blue light and UV-A [27]. Phytochromes are photochromic proteins that exist as two photo-interconvertible isomeric forms: the red-light-absorbing form (Pr) and the far-red-light-absorbing form (Pfr) [28]. Upon excitation by R or FR light (producing a high or low R:FR value, respectively), phytochrome converts Pr into Pfr or vice versa [28]. Phytochromes exist predominantly in the Pfr form in daylight and $\operatorname{Pr}$ form overnight, as dictated by the process of dark recovery [29]. The conversion between $\mathrm{Pr}$ and Pfr is used to synchronize plant development to the light environment. When phyB mutations occurred in the LDPs Arabidopsis [30] and pea [31] as well as the SDPs sorghum [32] and rice [33], early flowering occurred, with decreased photoperiodic sensitivities. Accordingly, phyB delays flowering by suppressing the expression of $F T$-like genes in LDPs and SDPs [21, 34]. There are five phytochromes in tomato: phyA, phyB1, phyB2, phyE, and phyF [35]. PHYB1 is involved in many tomato physiological and biological processes, such as de-etiolation, hypocotyl hook unfolding, cotyledon expansion, hypocotyl elongation, anthocyanin accumulation, and flowering $[6,35]$. However, the functions of these phytochromes in integrating environmental signals into tomato flowering still remains unclear and requires further investigation.

Four expressed FT-like proteins, SP3D, SP5G, SP5G2, and SP5G3, have been identified previously by our lab, and they play important roles in tomato flowering [6]. Overexpression of these genes in Arabidopsis revealed that SP3D is a floral promoter, while SP5G, SP5G2, and SP5G3 are floral repressors [6]. To further study their roles in tomato flowering under different light conditions (i.e., NB and different R:FR values), we initially established the conditions required for efficient $\mathrm{NB}$ and R:FR values to impact flowering in tomato. The expression of $F T$-like genes after NB treatment and different R:FR values have been investigated in wild type (WT) and phytochrome mutants. The results clearly show that the increased SP5G mRNA is the principal cause of the $\mathrm{NB}$ and R:FR ratio effects on late flowering in tomato. Phytochrome B1 transduces the NB and R:FR signals, thereby influencing flowering.

\section{Results \\ Overexpression of SP5G, SP5G2, and SP5G3 delayed flowering in Nicotiana benthamiana}

We have previously reported that overexpression of SP5G, SP5G2, and SP5G3 resulted in delayed flowering in transgenic Arabidopsis plants relative to WT controls [6]. To further investigate the functions of SP3D, SP5G, SP5G2, and SP5G3 in flowering, we overexpressed tomato SP3D, SP5G, SP5G2, and SP5G3 genes into Nicotiana benthamiana. Overexpression of $S P 3 D$ leads to early flowering in transgenic Nicotiana benthamiana (Fig. 1a). However, overexpression of SP5G, SP5G2, or SP5G3 delays flowering in transgenic Nicotiana benthamiana 


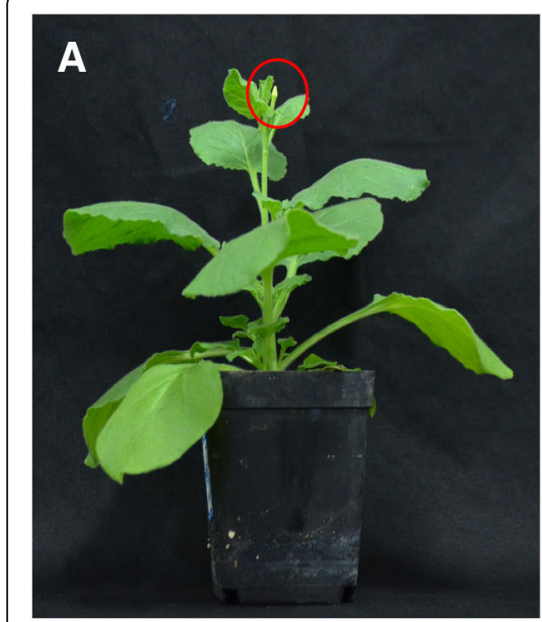

WT

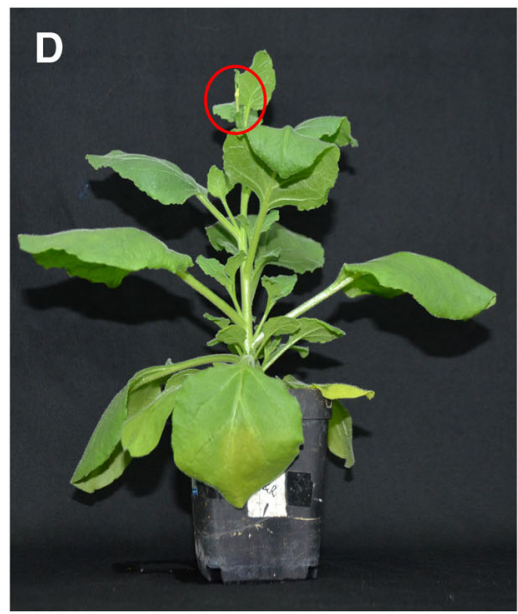

35S::SP5G2

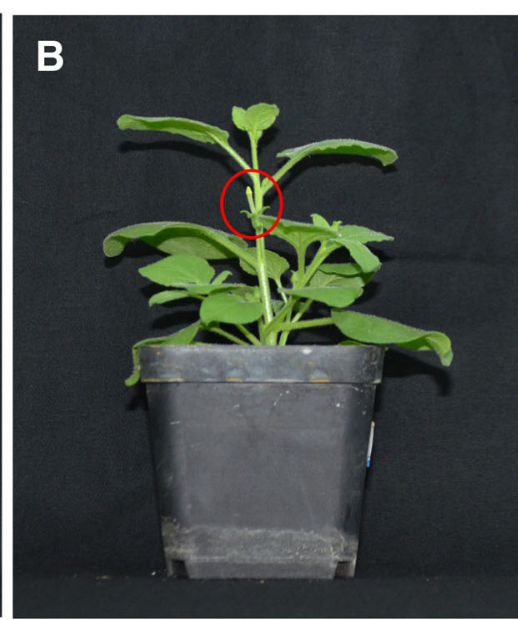

$35 S:: S P 3 D$

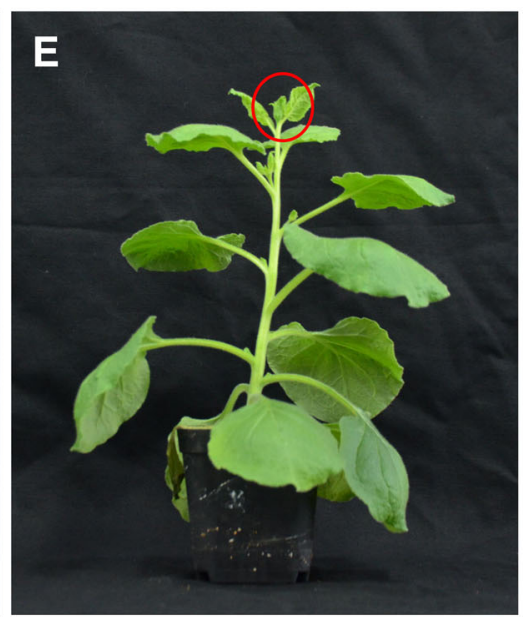

35S::SP5G3

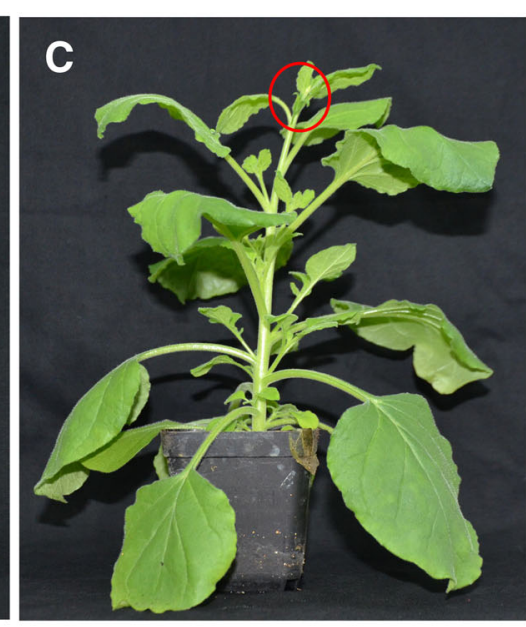

$35 S:: S P 5 G$

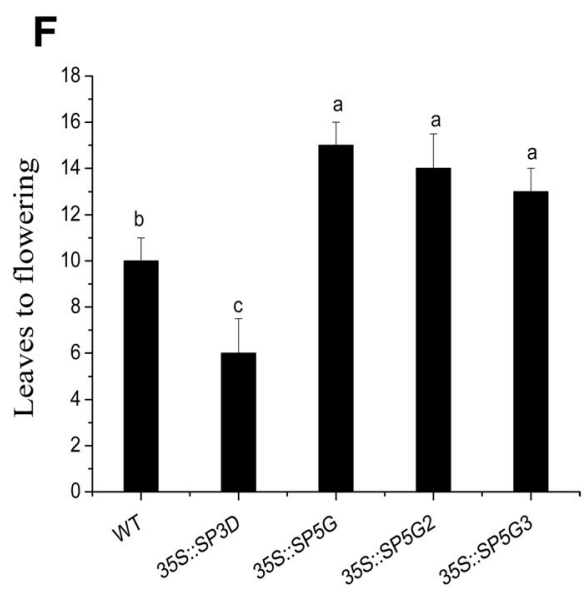

Leaf stage at flowering

Fig. 1 Overexpression of tomato SP3D promotes flowering, while overexpression of tomato SP5G, SP5G2, or SP5G3 genes delay flowering in transgenic Nicotiana benthamiana. a WT, (b) SP3D overexpression line, (c) SP5G overexpression line, (d) SP5G2 overexpression line, (e) SP5G3 overexpression line, (f) leaf stage at flowering in SP3D, SP5G, SP5G2, and SP5G3 Nicotiana benthamiana overexpression lines under DN conditions. The red circles indicate flowers. Vertical bars represent the SE $(n=5)$. Bars with different letters are significantly different at the 0.05 level according to Duncan's multiple range test

(Fig. 1b, c, d). Under day-neutral (DN) conditions, flowering occurs at the 10-leaf stage in WT plants. However, flowering occurred at the 6-leaf stage in SP3D-overexpressing plants, whereas flowering was delayed until the 15-leaf stage in SP5G-overexpressing plants, 14-leaf stage in SP5G2-overexpressing plants and 13-leaf stage in SP5G3-overexpressing plants under DN conditions (Fig. 1). These results indicate that SP3D promotes flowering, while SP5G, SP5G2, and SP5G3 repress flowering. GUS ( $\beta$-glucuronidase) staining can understand the organ, tissue and cell specificity of gene expression in transgenic plants. Transgenic Arabidopsis plants that carrying SP3D-GUS, SP5G-GUS, SP5G2-GUS, and SP5G3-GUS genes were stained to check GUS activity. All tested lines showed identical patterns of GUS staining, and differences were observed only in staining intensity. Histochemical examination of the transgenic SP3D-GUS, SP5G-GUS, SP5G2-GUS, and SP5G3-GUS Arabidopsis plants indicated that all transgenes were expressed in the vascular tissue of most of their organs (Fig. 2).

\section{Effects of NB and R:FR on flowering in tomato}

To initiate a molecular-genetic study of the NB response in tomato, we first determined which NB frequencies and $\mathrm{R}$ light intensities elicited the most sensitivity to NB. We grew tomato seedlings under $\mathrm{DN}$ conditions, and the NB treatment was conducted from seed germination until flowering. Each burst of NB treatment lasted 10 min under various frequencies, which included NB 


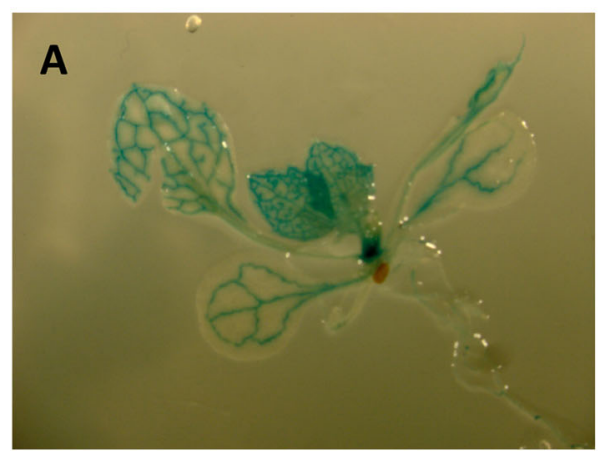

SP3D::GUS

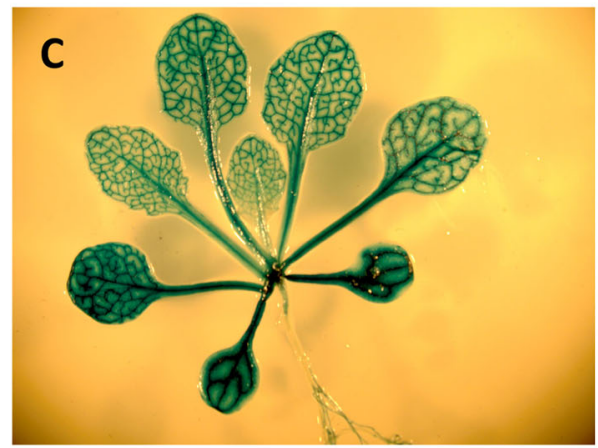

SP5G2::GUS

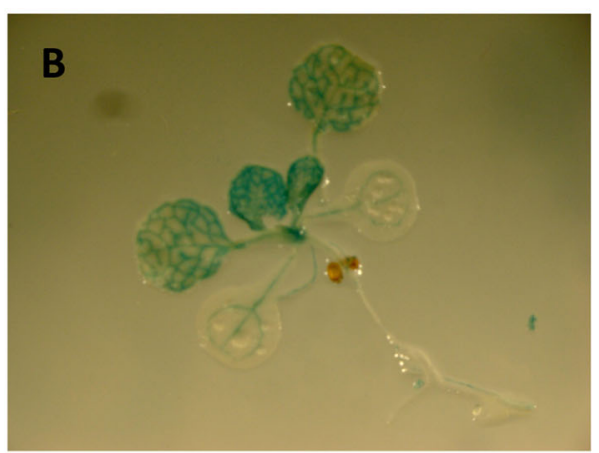

SP5G::GUS

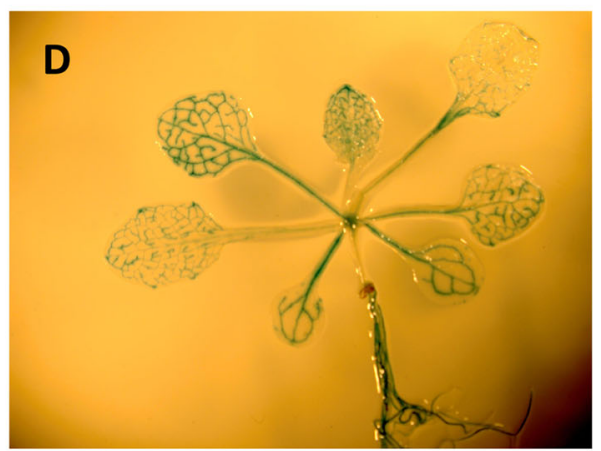

SP5G3::GUS

Fig. 2 SP3D-GUS, SP5G-GUS, SP5G2-GUS, and SP5G3-GUS activity in transgenic Arabidopsis thaliana. GUS-activity was visualized with the chromogenic substrate X-Gluc. a SP3D-GUS, (c) SP5G-GUS, (c) SP5G2-GUS, and (d) SP5G3-GUS

every $1,2,3$, or $4 \mathrm{~h}$ during the night at the intensities of $10 \mu \mathrm{mol} \mathrm{m} \mathrm{m}^{-2} \mathrm{~s}^{-1}$ and $50 \mu \mathrm{mol} \mathrm{m} \mathrm{m}^{-2} \mathrm{~s}^{-1}$. As a control, plants were raised with dark periods lacking NB. The leaf stage at flowering was recorded for both experimental and control plants. The NB effect on delayed flowering was detectable even when NB occurred every $3 \mathrm{~h}$ throughout the night (Fig. 3a). However, the strongest flowering delay effects occurred at the NB frequencies of $1 \mathrm{~h}$ and $2 \mathrm{~h}$. NB at a light intensity of $10 \mu \mathrm{mol} \mathrm{m}^{-2} \mathrm{~s}^{-1}$ had a clear inhibitory effect on flowering in tomato. We next tested the effects of $\mathrm{NB}$ at a light intensity of $50 \mu \mathrm{mol} \mathrm{m} \mathrm{m}^{-2} \mathrm{~s}^{-1}$ on the inhibition of flowering. There was no clear difference in delay of flowering between the two light intensities (Fig. 3a).

For the R:FR experiments, tomato seedlings were grown under white LEDs alone or supplemented with FR LEDs. The R:FR ratios were 7.4, 1.2, and 0.6. A R:FR value of 0.6 is in the range of what plants might experience growing under a canopy [24]. In this study, we found that tomato seedlings grown under FR-enriched light conditions can exhibit delays in flowering while higher R:FR values (i.e., 7.4) lead to earlier flowering in tomato seedlings, relative to lower R: FR values (i.e., 0.6; Fig. 3b).

\section{FT-like gene expression under the NB and R:FR treatments}

To examine the effects of NB and R:FR on gene expression, we assayed the expression of four FT-like genes that are important floral regulators in tomato. Previous studies have revealed that SP3D/SFT is a floral activator in tomato, while SP5G, SP5G2, and SP5G3 are floral repressors [6]. We measured the mRNA levels of the four FT-like genes by real time PCR over a 24-h period under DN conditions in the presence or absence of $\mathrm{NB}$ and different R:FR values.

For the NB experiments, we applied 10 min of $\mathrm{R}$ light at a 2-h frequency throughout the 12-h night period. After the NB treatment, the expression of SP5G mRNA was strongly promoted during the day and night (Fig. 4b). Under normal conditions, SP5G mRNA was expressed at a very low level during the day and night. In contrast with SP5G mRNA, no clear effect was found on SP3D and SP5G2 mRNA, and SP5G3 mRNA showed the opposite pattern, i.e., a decrease after NB treatment (Fig. 4a, c, d). Therefore, the increased SP5G mRNA level likely delayed flowering in tomato plants under the NB treatment. 


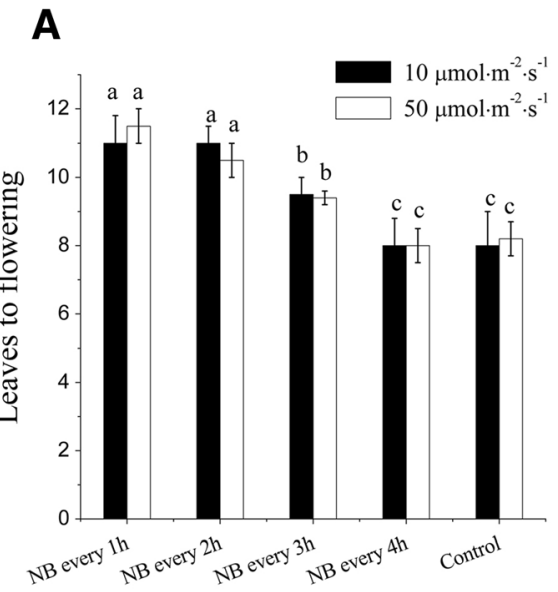

NB Treatments

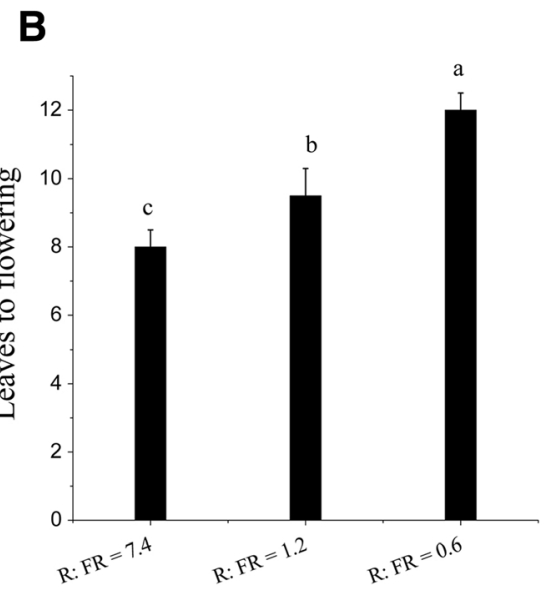

Different R: FR ratio treatments

Fig. 3 Effects of night break (NB) and different red-to-far-red light ratio (R:FR) treatments on the leaf stage at flowering in tomato plants. a Leaf stage at flowering under NB treatments every 1, 2, 3, or $4 \mathrm{~h}$ at one of two R light intensities, either $10 \mu \mathrm{mol} \mathrm{m} \mathrm{m}^{-2} \mathrm{~s}^{-1}$ or $50 \mu \mathrm{mol} \mathrm{m} \mathrm{m}^{-2} \mathrm{~s}^{-1}$. b Leaf stage at flowering for R:FR treatments, in which R:FR values are 7.4, 1.2, and 0.6. Vertical bars on the lines represent the SE $(n=10)$. Bars with different letters are significantly different at the $P<0.05$ significance level according to Duncan's multiple range test
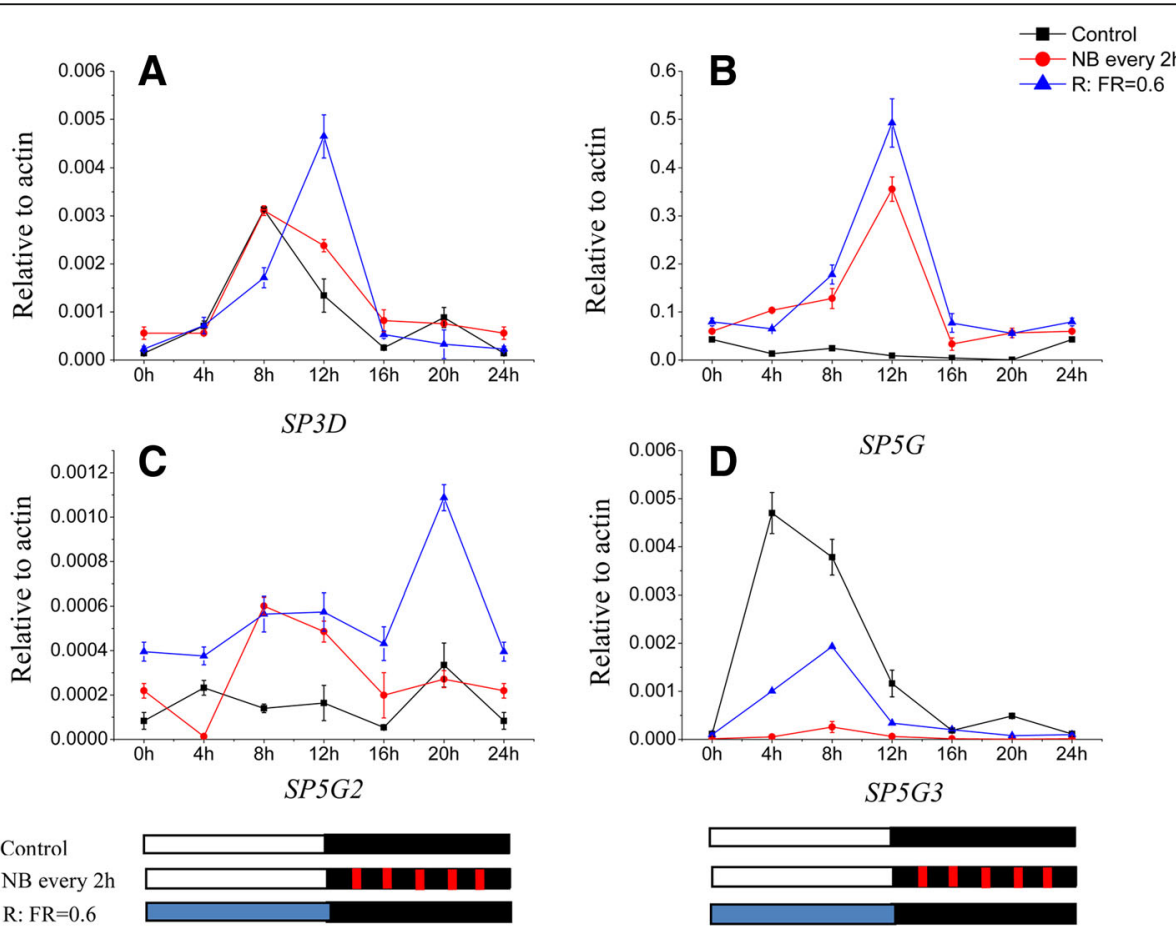

Control
NB every $2 \mathrm{~h}$
R: FR $=0.6$
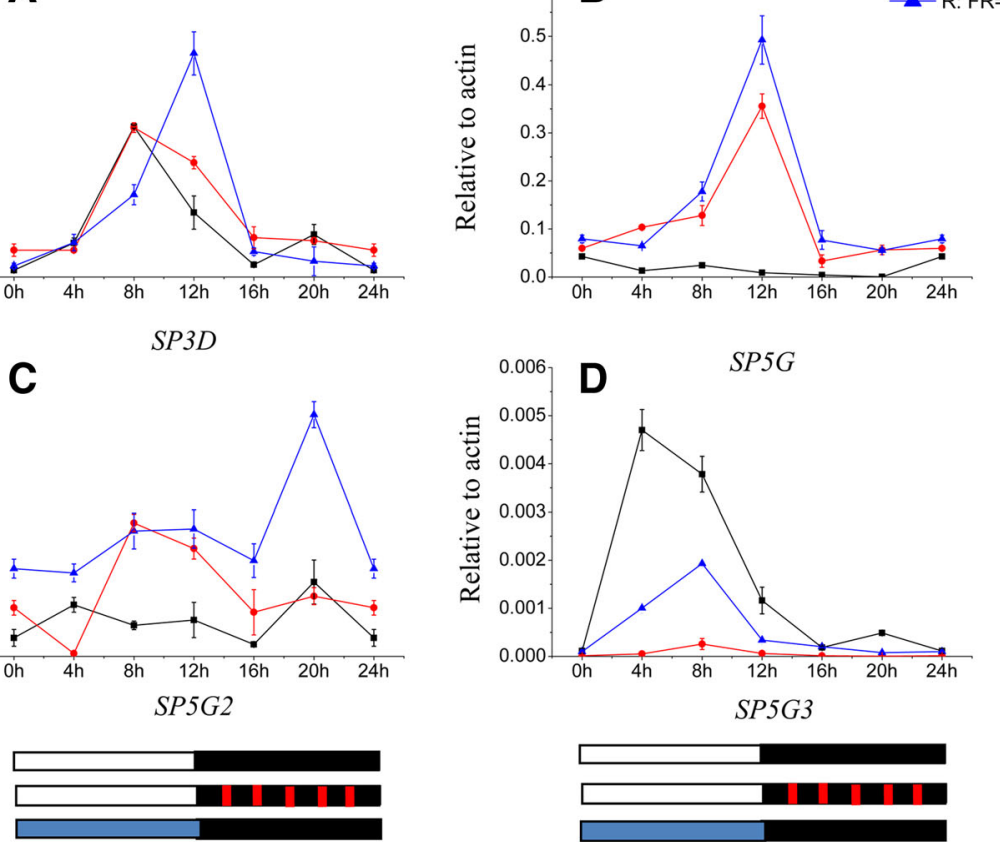

Fig. 4 Diurnal expression of tomato SP3D (a), SP5G (b), SP5G2 (c), and SP5G3 (d) by night break (NB) and red-to-far-red light ratio (R:FR) treatments under day neutral (DN) conditions ( $12 \mathrm{~h}$ light/12 h dark), respectively. The black line represents the control (R:FR value is 7.4), the red line represents NB every $2 \mathrm{~h}$, and the blue line represents a R:FR value of 0.6. Leaves were harvested from plants at 4-h intervals. The vertical axis shows relative mRNA levels of FT-like genes normalized to the expression of Actin. Error bars represent the standard error among technical replicates. White, black, red and blue bars at the bottom indicate light, dark red and far-red light periods, respectively 
For the R:FR experiment, we supplied $12 \mathrm{~h}$ of supplemental FR light to produce R:FR values of 7.4 in the control and 0.6 in the treatment during the daytime. Under the FR-enriched light conditions, SP5G and SP5G2 mRNA expression was strongly promoted during the day and night (Fig. 4b, c). However, SP5G3 mRNA remained at a low level during the day and night under the lower R:FR value, and there was no significant influence on SP3D mRNA expression under the different R:FR values (Fig. 4a, d). Therefore, the increased SP5G and SP5G2 mRNA levels may have delayed flowering in tomato plants under the lower R:FR value.

\section{The expression of SP5G mRNA can be reversed by R and FR light}

SP5G was recently shown to repress flowering, and it played a very important role in photoperiod response in tomato, so we focused on SP5G for further investigations [36]. To determine the length of the NB effect on SP5G mRNA expression, we examined SP5G mRNA at the end of light for 3 days without NB treatment after 2 weeks of $\mathrm{R}$ light $\mathrm{NB}$ treatments. The promotion of SP5G mRNA expression under the NB treatment completely disappeared by the next day after the NB treatment had been discontinued (Fig. 5a). To determine whether the increased expression of SP5G mRNA induced by $\mathrm{R}$ light NB can be reversed by FR light, we examined SP5G mRNA after exposure to $10 \mathrm{~min}$ of $\mathrm{R}$ light plus $10 \mathrm{~min}$ of FR light. SP5G mRNA was promoted by $\mathrm{R}$ light, and the NB effect was reversed by FR light (Fig. 5b). These results together clearly demonstrated that the upregulated SP5G mRNA expression is the basis of $\mathrm{R}$ light $\mathrm{NB}$ and that it influences tomato flowering.

To determine the duration of the FR light effect on SP5G mRNA expression after the cessation of FR light treatment, we examined SP5G mRNA in tomato plants grown under lower R:FR conditions for 2 weeks and then transferred them to higher R:FR light conditions for 3 days. The promotion of SP5G mRNA expression
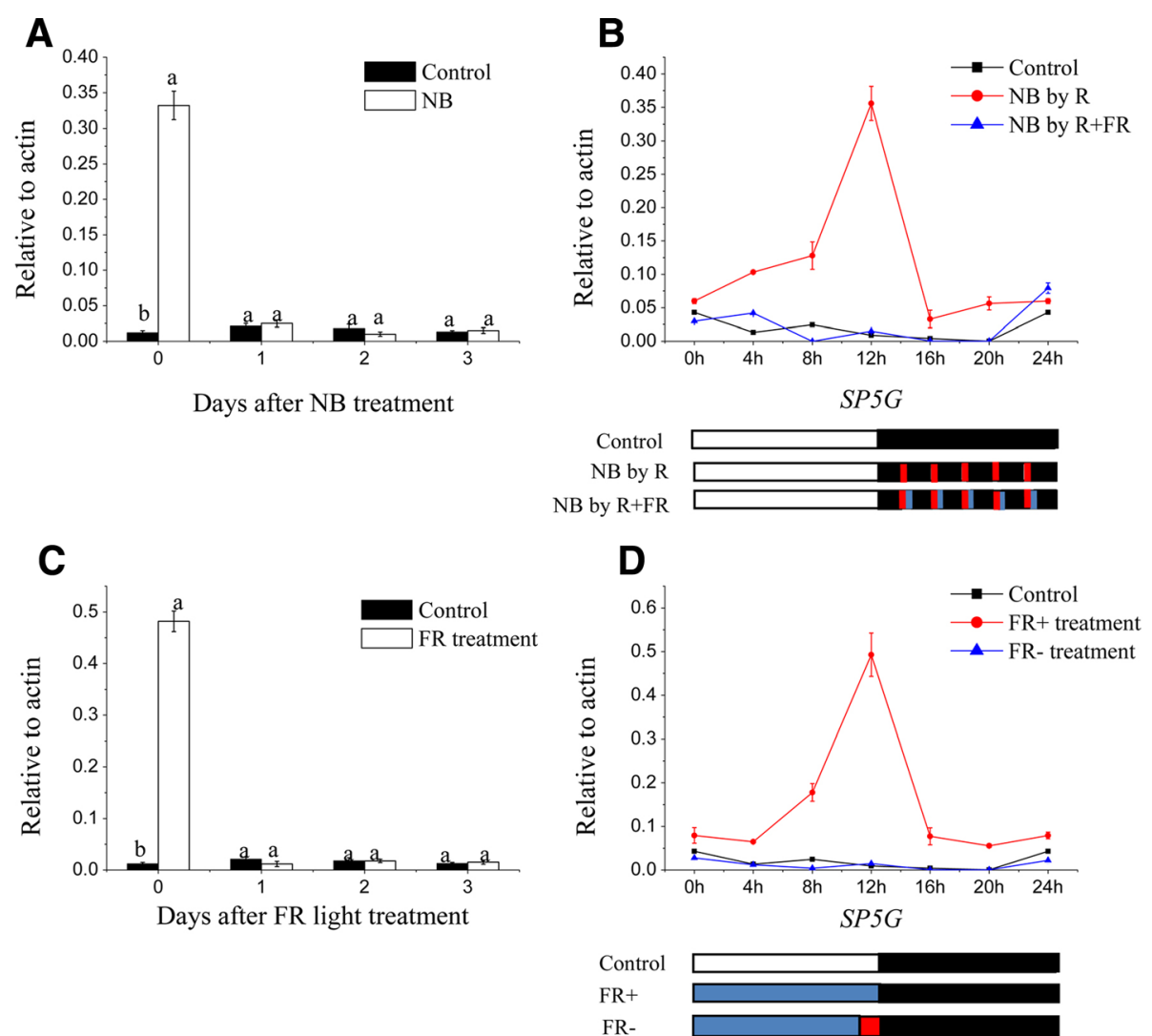

Fig. 5 SP5G expression analysis conducted by qRT-PCR in tomato plants under different light treatments and DN conditions. a The expression of SP5G mRNA at 1, 2, and 3 days after the cessation of red (R) light night break (NB). $\mathbf{b}$ The diurnal expression of SP5G mRNA when tomato plants were treated by $R$ light NB and red and far red $(R+F R)$ light NB, respectively. $\mathbf{c}$ The expression of SP5G mRNA at 1, 2, and 3 days after cessation of far red (FR) light. $\mathbf{d}$ The diurnal expression of SP5G mRNA when tomato plants were treated with FR light and FR light was ended. All data are expressed as means \pm SE of three independent pools of extracts. Three technical replicates were performed for each extract. Bars with different letters are significantly different at the $P<0.05$ level according to Duncan's multiple range test. White, black, red and blue bars at the bottom indicate light, dark red and far-red light periods, respectively 
induced by lower R:FR values completely disappeared by the end of light in the following day after their transfer to higher R:FR conditions (Fig. 5c). To test whether the increased expression of SP5G mRNA in FR light-enriched condition can be reversed by $\mathrm{R}$ light, we examined SP5G mRNA expression after 10 min of FR light followed by cessation of the FR LED light. After the FR LED light was stopped, the expression of SP5G mRNA was almost at the same level as the control because white LEDs have a high R:FR ratio and phytochromes can convert Pr to Pfr under these conditions (Fig. 5d). The expression of SP5G mRNA was controlled by R:FR values in the day time and influenced tomato flowering.

\section{Phytochrome B1 is responsible for the effects of NB and R:FR on flowering and SP5G mRNA expression}

Since the initial discovery of the NB effect on flowering, it has been well established that phytochrome is an important photoreceptor associated with the NB response [37]. The response to different R:FR values and shade is primarily regulated by phytochrome [38]. Therefore, we tested whether the NB and R:FR treatment effects on SP5G mRNA expression are mediated by phytochrome. Flowering time and SP5G mRNA expression were analyzed in WT plants as well as phyA, phyB1, and phyB2 mutants after NB and under different R:FR treatments. The results on the effects of different phytochrome mutations on flowering under $\mathrm{NB}$ and different R:FR conditions clearly indicated that phyB1 is responsible for mediating the NB and different R:FR effects on the delay of flowering (Fig. 6e, f). The phyA and phyB2 mutants flowered at leaf stages that were similar to those of the WT, while there were no effects on the flowering phenotype under the $\mathrm{NB}$ treatment and various R:FR treatments (Fig. 6a-d, g, h). Similarly, the NB and R:FR effects on the promotion of SP5G mRNA were abolished in phyB1 mutants (Fig. 6f), whereas there was no clear, observable effect in phyA and phyB2 mutants (Fig. 6d, h). Together, these results clearly demonstrated that phyB1 is responsible for delayed flowering and that SP5G mRNA expression was caused by the NB and R:FR treatments in tomato.

\section{Discussion}

In the present study, overexpression of SP5G, SP5G2, or SP5G3 in Nicotiana benthamiana delayed flowering relative to control plants (Fig. 1). Our previous phylogenetic analyses revealed that SP5G, SP5G2, and SP5G3 are $F T$-like genes [6]. FT-like proteins form a sub-clade of phosphatidylethanolamine-binding proteins (PEBPs) and work as flower activators in many species [7-16]. Similar $F T$-like genes that function as floral repressors have been reported previously in Beta vulgaris (sugar beet) and Nicotiana tabacum. There are two FT-like genes in sugar beet, $B v F T 1$ and $B v F T 2$, and they differ in three critical amino acid residues [10]. Tyr (134), Gly (137), and Trp (138) are the three most important amino acids BvFT2 proteins, and the modification of BvFT1 Asn (138) into Tyr, Gln (141) into Gly, and Gln (142) into Trp can completely revert its repressing function, thereby promoting flowering (Additional file 1: Figure S1) [10]. Amino acid sequence analysis revealed that tomato SP5G, SP5G2 and SP5G3 were not conserved, but SP3D are conserved in the three critical amino acid residues as observed in the BvFT2 protein (Additional file 1: Figure S1). The change of the ciritical amino acid may have resulted in SP5G, SP5G2, and SP5G3 becoming floral repressors (Additional file 1: Figure S1). One essential functional feature of $F T$-like genes is their expression in leaf vasculature and transport of the translated protein into the shoot apex. The expression of SP5G, SP5G2 and SP5G3 were detected mainly in vascular tissues (Fig. 2). According to the current model established in Arabidopsis and rice, FT-like genes are transcribed and translated in leaf vasculature and then move via the phloem to the shoot apical meristem, where they interact with an FD bZIP transcription factor to induce flowering $[2,3]$.

NB treatment and different R:FR values influence on plant flowering have been known for a long time $[19,21,26]$. Our results clearly demonstrate that NB every $2 \mathrm{~h}$ and lower R:FR values promote the subsequent accumulation of SP5G transcripts, resulting in a delay in tomato flowering (Figs. 3, 4). The effect of NB on flowering is most evident in SDPs, in which it inhibits $F T$-like gene expression, thus repressing flowering through a very short exposure of light during the night, especially by $\mathrm{R}$ light or high $\mathrm{R}: \mathrm{FR}$ light [20, 22, 39]. In contrast, NB treatments promote flowering in LDPs, which consist of only a limited number of species that generally require longer light exposure times [19, 40]. Tomato is a DNP, and it accordingly flowers regardless of photoperiod, but flower initiation occurs earlier under SD conditions than LD conditions. In this study, when tomato seedlings are subjected to NB treatment, the leaf stage at flowering increased from 8 to 11 leaves, and SP5G mRNA expression significantly increased compared with the control. In nature, the values of R:FR can be used to sense proximity of neighboring plants or canopy vegetation, changes in day length, and seasonal variation, each of which influence flowering $[24,41]$. Several studies have shown that the presence of FR light promotes flowering of LDPs, such as tussock bellflower (Campanula carpatica) and tickseed (Coreopsis grandiflora) [42], in which flowering was delayed when grown under photoselective filters that created an FR-deficient environment during the entire day. In contrast, the flowering of SDPs, such as strawberry 

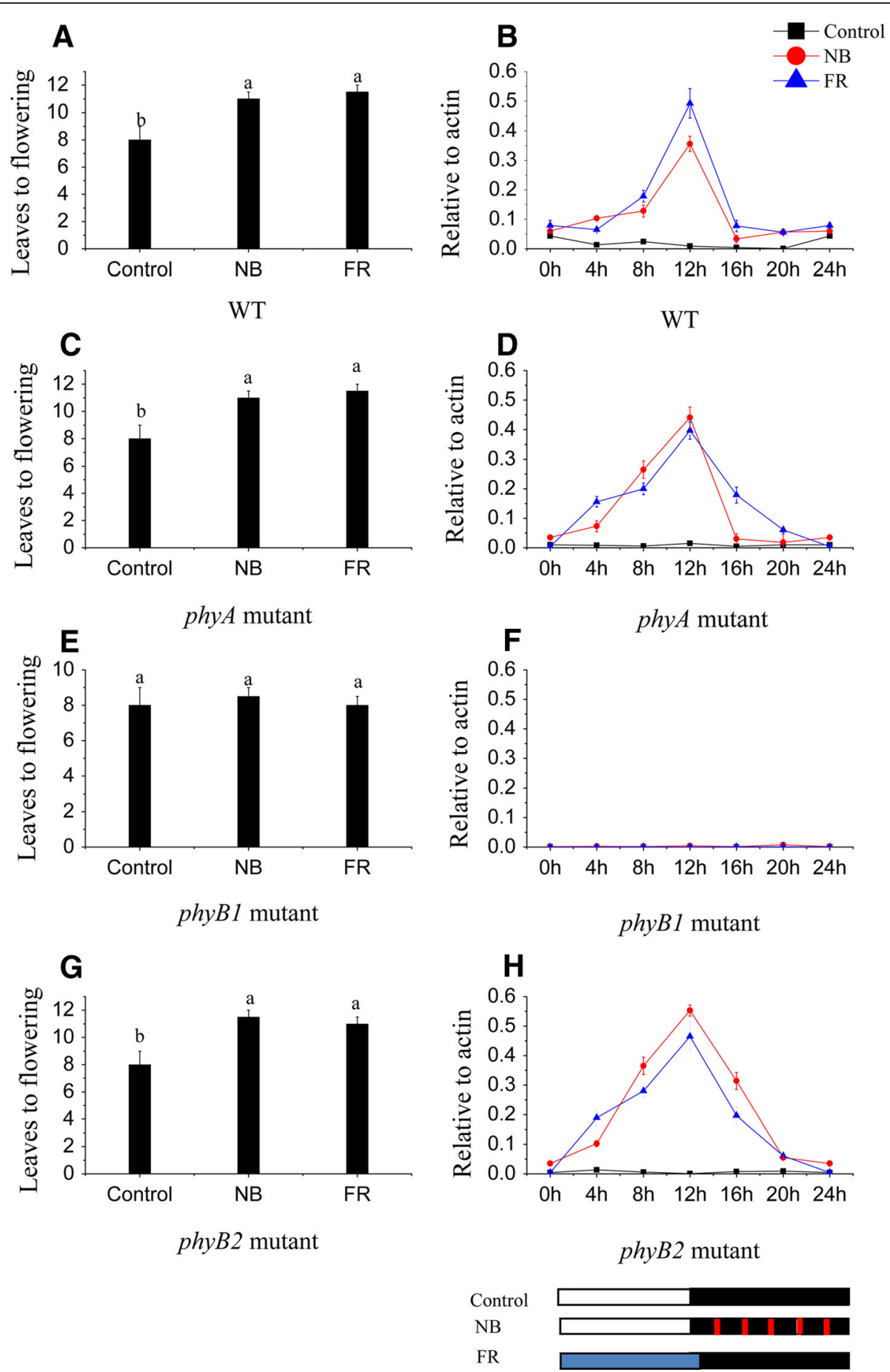

Fig. 6 Phytochrome B1 is responsible for the expression of SP5G and influences the flowering of tomato plants by night break (NB) and different red-to-far-red light (R:FR) treatments. The leaf stage at flowering in tomato for (a) WT plants as well as (c) phyA, (e) phyB1, and (g) phyB2 mutants treated by NB and different R:FR treatments. Data are mean \pm SE of 10 plants. Bars with different letters are significantly different at the $P<0.05$ significance level according to Duncan's multiple range test. The diurnal expression of SP5G in tomato for (b) WT plants as well as (d) phyA, (f) phyB1, and (h) phyB2 mutants treated by NB and different R: FR treatments. Data are expressed as means \pm SE of three independent pools of extracts. Three technical replicates were performed for each extract. White, black, red and blue bars at the bottom indicate light, dark red and far-red light periods, respectively 
[43], duckweed (Lemna paucicostata) [44] and chrysanthemum (Chrysanthemum grandiflorum) [45] were influenced by FR light environments. In this study, when tomato seedlings were subjected to lower R:FR treatments, the leaf stage at flowering increased from 8 to 11.5 leaves, and SP5G mRNA expression significantly increased compared with the control (Figs. 3, 4). Previous studies have reported similar findings of $F T$-like gene expression being influenced by different R:FR values [24-26].

Phytochromes are known to mainly perceive $R$ and FR light, which influence plant growth and flowering in several crops [21, 46-48]. In chrysanthemum and soybean, flowering can be inhibited by $\mathrm{R}$ light NB treatment, which promotes the conversion of phytochrome to Pfr, thus inhibiting flowering. However, after a subsequent FR exposure, flowering inhibition imposed by $\mathrm{R}$ light could be reversed $[49,50]$. Our results clearly demonstrated that the delayed flowering phenotype and increased SP5G mRNA expression induced by R light NB or lower R:FR treatment was reversed by subsequent FR light exposure or higher R:FR treatments (Fig. 5). These results indicated that phytochrome is involved in tomato flowering and SP5G mRNA expression by R light NB and different R:FR value treatments. In Arabidopsis, phytochrome B delays flowering by suppressing $F T$ expression [34]. In rice, phyB is responsible for the delayed flowering and $H d 3 a$ mRNA suppression caused by NB treatments [21]. In this study, we found phyB1 is required for NB and lower R:FR value treatments to suppress flowering and promote SP5G mRNA expression, whereas $p h y A$ and phyB2 have no effect on tomato flowering and SP5G mRNA expression via NB and various R:FR treatments. This suggests that phyB1 is the critical phytochrome that controls tomato flowering and SP5G mRNA expression (Fig. 6). Various light signal components have been shown to control CO stability throughout the day. FR light signals stabilize CO, R light signals destabilizes $\mathrm{CO}$, and phyB is involved in $\mathrm{CO}$ degradation $[47,51]$. Recent evidence has suggested that the function of PHYTOCHROME DEPENDENT LATE FLOWERING (PHL) counteracts the ability of phyB to regulate flowering, suggesting that the changes in $\mathrm{CO}$ stability are mediated by phyB [52]. Therefore, it is possible that the NB and different R:FR effects may be regulated by phyB by controlling the stability of the CO-like protein in tomato.

\section{Conclusion}

In summary, we found SP5G, SP5G2, and SP5G3 are FT-like genes, but overexpression of tomato SP5G, SP5G2, and SP5G3 delays flowering in transgenic Nicotiana benthamiana. NB and lower R:FR treatments lead to delayed flowering phenotypes and increased SP5G mRNA expression in tomato, and phyB1 is required for this. We determined that SP5G is important for tomato flowering and that it is controlled by phyB1, which plays a very important role in integrating $\mathrm{NB}$ and R:FR signals. The present study provides a deeper understanding of the response of tomato flowering to different light conditions.

\section{Methods}

\section{Plant material and growth conditions}

The tomato variety MoneyMaker (Solanum lycopersicum L.) was used in this study. The MoneyMaker mutant backgrounds $p h y A$, phyB1, and phyB2 were provided by the Tomato Genetic Resource Center (Department of Vegetable Crops, University of California, Davis; TGR accession numbers LA4356, LA4357, and LA4358, respectively). Tomato seeds were soaked in $50 \%$ bleach for $30 \mathrm{~min}$. After bleaching, seeds were rinsed thoroughly in running water, then sown directly onto moistened germination paper and incubated at $25^{\circ} \mathrm{C}$. After germination, seeds were sown into commercial substrate and grown in growth chambers for each of the different treatments.

\section{NB and FR treatments}

For the NB studies, tomato seedlings were grown in growth chambers at $60 \%$ humidity under a photoperiod with daily cycles of $12 \mathrm{~h}$ of light at $25{ }^{\circ} \mathrm{C}$ and $12 \mathrm{~h}$ of darkness at $25{ }^{\circ} \mathrm{C}$. Light was generated by an LED light source $\left(400-700 \mathrm{~nm}, 200 \mu \mathrm{mol} \mathrm{m}{ }^{-2} \mathrm{~s}^{-1}\right)$. NB experiments were performed in the growth chambers using red LEDs (658 nm peak) with a light intensity of $10 \mu \mathrm{mol} \mathrm{m}{ }^{-2} \mathrm{~s}^{-1}$ and $50 \mu \mathrm{mol} \mathrm{m} \mathrm{s}^{-2} \mathrm{~s}^{-1}$ at a NB stimulus delivered every $1,2,3$, or $4 \mathrm{~h}$ throughout the night. For R:FR studies, tomato seedlings were grown at $25{ }^{\circ} \mathrm{C}$ with $60 \%$ humidity and under $200 \mu \mathrm{mol} \mathrm{m} \mathrm{m}^{-2} \mathrm{~s}^{-1}$ (400$700 \mathrm{~nm})$ LED lights with or without supplemental far-red LEDs (730 nm peak), to yield R:FR values are 7.4, 1.2 , and 0.6 as R:FR = (photon irradiance between 655 and $665 \mathrm{~nm}$ ) / (photon irradiance between 725 and $735 \mathrm{~nm}$ ). Light spectra were measured using a spectroradiometer (PAR-NIR; Apogee Instruments Inc., Logan, UT). The R light intensity and spectrum are shown in Fig. 7. The tomato seedlings were sub-irrigated every 3 days throughout the treatment with Yamasaki nutrient solution ( $\mathrm{pH} 6.5 \pm 0.1$, electrical conductivity: $1.4-1.8 \mathrm{dS}$ $\mathrm{m}^{-1}$ ) containing $4 \mathrm{mmol} / \mathrm{L} \mathrm{NO}_{3}-\mathrm{N}, 0.7 \mathrm{mmol} / \mathrm{L} \mathrm{NH}_{4}-\mathrm{N}$, $0.7 \mathrm{mmol} / \mathrm{L} \mathrm{P}, 4 \mathrm{mmol} / \mathrm{L} \mathrm{K}, 1.0 \mathrm{mmol} / \mathrm{L} \mathrm{Mg}, 1.7 \mathrm{mmol} /$ $\mathrm{L} \mathrm{Ca}$, and $2.7 \mathrm{mmol} / \mathrm{L} \mathrm{S}$ as well as micro nutrients.

\section{RNA and DNA extraction}

Tomato leaves were harvested at the end of the light, pooled from 3 third leaves of 5-week old plants, and total RNA was extracted using an RNeasy Plant mini kit (Takara, Dalian, China) following the manufacturer's 


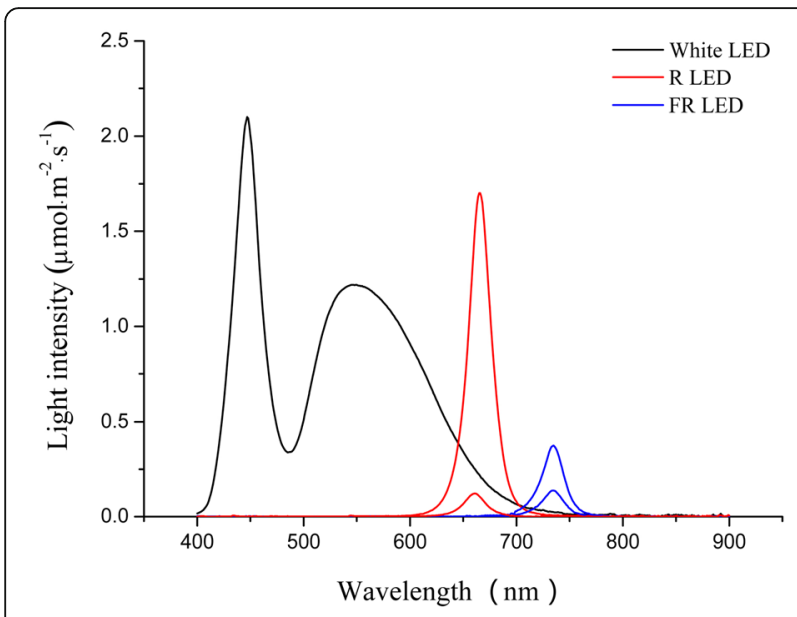

Fig. 7 Spectral distribution characteristics of white, red (R) and far red (FR) LEDs used for night break (NB) and different R:FR treatments. The black curve represent white LED light; the two red curves represent two R light intensity, 10 and $50 \mu \mathrm{mol} \cdot \mathrm{m}^{-2} \cdot \mathrm{s}^{-1}$; and the two blue curves represent supplemental FR light to make R:FR values were 1.2 and 0.6

instructions. Plant genomic DNA was isolated using an Easy Pure Plant Genomic DNAkit (TransGen, Beijing, China) according to the manufacturer's instructions.

Gene isolation, vector construction, and plant transformation The ORFs of SP3D(Solyc03g063100), SP5G (Solyc05g 053850), SP5G2 (Solyc11g008640), SP5G3 (Solyc11g00 8650) were PCR amplified from the cDNA of MoneyMaker, cloned into a pENTR/3C vector (Invitrogen, Shanghai, China), and then subcloned into the pBCO-DC vector by recombination using the LR Clonase enzyme (Invitrogen, Shanghai, China). pBCO-DC carries a spectinomycin resistance gene for bacterial selection and a Basta resistance gene for selection of transformed plants. To express GUS under the control of tomato SP3D, SP5G, SP5G2, and SP5G3 promoters, 3000 bp of $5^{\prime}$ upstream sequence of these genes was amplified from MoneyMaker genomic DNA, cloned into a $\mathrm{pENTR} / 3 \mathrm{C}$ vector, and then transferred into a pK7WGF2 vector [53] by recombination using the LR Clonase enzyme. The bacterial resistance of pK7WGF2 is spectinomycin, and plant selectable marker is kanamycin. The primers used are listed in Additional file 1: Table S1. The plasmid mediated by Agrobacterium tumefaciens strain CV3101 was transformed into Nicotiana benthamiana and Arabidopsis thaliana. Transformed plants were selected on $0.8 \%$ agar media containing Murashige and Skoog salts, $0.5 \mathrm{~g} / \mathrm{L}$ MES, and $10 \mathrm{~g} / \mathrm{L}$ sucrose containing $10 \mu \mathrm{g} \mathrm{ml}^{-1}$ basta or kanamycin. After screening for regenerated shoots on selection medium containing basta or kanamycin, the transgenic plants were further verified by PCR using genomic DNA as a template and $35 \mathrm{~S}$ forward and gene-specific reverse primers.

\section{$\beta$-glucuronidase (GUS) activity assay}

Seedlings were grown on selected MS media with Kana antibiotics until they reached the 3-4 true leaf stage. For the histochemical GUS assay, the seedlings were incubated in X-GLUC reaction buffer (2 mM X-GLUC [5-bromo-4-chloro-3-indolyl- $\beta$-d-glucuronide cyclohexylamine salt)] $1 \mathrm{mM}$ EDTA, $50 \mathrm{mM} \mathrm{NaPO}, 0.5 \mathrm{mM} \mathrm{K}{ }_{3} \mathrm{Fe}(\mathrm{CN})_{6}$, $0.5 \mathrm{mM} \mathrm{K}_{4} \mathrm{Fe}(\mathrm{CN})_{6}$, and $1 \%$ Triton $\left.\mathrm{X}-100\right)$ overnight at $37{ }^{\circ} \mathrm{C}$. The seedlings were cleared by a series of ethanol extractions after an overnight reaction, and blue precipitates were examined under a dissecting microscope.

\section{Gene expression studies}

For study the diurnal expression of SP3D, SP5G, SP5G2, and SP5G3 genes, tomato leaves were harvested every $4 \mathrm{~h}$ for $24 \mathrm{~h}(0,4,8,12,16,20$, and $24 \mathrm{~h})$, pooled from 3 third leaves of 5-week old plants. Total RNA was extracted using an RNeasy Plant mini kit (Takara, Dalian, China) following the manufacturer's instructions. cDNA synthesis was performed by using the SuperscriptIII First strand synthesis system (Invitrogen, Shanghai, China) following the manufacturer's instructions. Real-time PCR was performed using SYBR Premix Ex Taq (Takara, Dalian, China) in a Bio-Rad CFX96 real-time PCR system (Bio-Rad, Hercules, CA, USA). As an internal control gene, actin transcripts were assayed. The primers used are listed in Additional file 1: Table S1. Real-time quantitative PCR was repeated three times, and each time every sample was assayed in triplicate by PCR.

\section{Statistical analysis}

Statistics were calculated using SPSS 20.0 (SPSS, version 20.0, IBM Inc., Armonk, NY, USA). The data were analyzed using an analysis of variance (ANOVA), and the differences between the means were assessed using Duncan's multiple range test $(P<0.05)$. Error bars in all figures represent standard deviations from the mean. Graphs were created using OriginPro (version 8.0, Origin Lab, Northampton, MA, USA).

\section{Additional file}

\begin{abstract}
Additional file 1: Table S1. Sequences of primers used in this study for plasmid construction and quantitative RT-PCR. Figure S1. Partial amino acid alignment of tomato $F T$-like sequences and other PEBP family proteins. Vertical arrowheads indicate amino acids essential for AtFT activity (Tyr85/GIn140) versus AtTFL1 activity (His88/Asp144). The red shaded area is part of exon 4, which encodes an external loop that has evolved very rapidly among TFL1 homologs, but is almost invariant in FT homologs. The yellow shaded area indicates amino acids that are important for the antagonistic activities of FT-like genes in tomato and sugar beet. (PDF $197 \mathrm{~kb}$ )
\end{abstract}

\section{Abbreviations}

DNPs: Day-neutral plants; FR: Far-red; GUS: $\beta$-glucuronidase; LDPs: Long day plants; NB: Night break; Pfr: Far-red-light-absorbing form; Pr: Red-lightabsorbing form; R: Red; R:FR: Red to far-red light ratio; SDPs: Short day plants 


\section{Acknowledgements}

We are grateful for tomato mutants obtained from the Genetic Resource Center (Department of Vegetable Crops, University of California, Davis). We thank Dr. Nam-Hai Chua and Dr. Shulin Deng for their suggestions in this study.

\section{Funding}

This research was funded by the study on key technologies for healthy production of efficient resources utilization in protected vegetables (2016BZ09), by research on key technologies and supporting equipment of protected vegetable production (CX161002), and by the achievement transformation of multilayer stereo water culture (AA16380048).

\section{Availability of data and materials}

Plant materials in this work and datasets analysed during the current study are available from the corresponding author upon request.

\section{Authors' contributions}

ZZ and KC conceived the study. ZZ and KC designed the experiments. KC carried out the gene overexpression, RNA expression and GUS staining studies. YF revised the manuscript. JY and DX carried out the DNA and RNA extraction studies. KA and EB interpreted the experimental data. All authors read and approved the final manuscript.

\section{Ethics approval and consent to participate}

Not applicable.

\section{Consent for publication}

Not applicable.

\section{Competing interests}

The authors declare that they have no competing interests.

\section{Publisher's Note}

Springer Nature remains neutral with regard to jurisdictional claims in published maps and institutional affiliations.

\section{Author details}

${ }^{1}$ The Agriculture Ministry Key Laboratory of Agricultural Engineering in the Middle and Lower Reaches of Yangze River, Jiangsu Academy of Agricultural Sciences, Nanjing, China. ${ }^{2}$ Shaanxi Key Laboratory Bio-resources, Shaanxi University of Technology, Hanzhong, Shaanxi, China. ${ }^{3}$ Horticulture College, Northwest A\&F University, Yangling, Shaanxi, China. ${ }^{4}$ Guangxi Zhong Nong Fu Yu International Agricultural Science and Technology Co., Ltd, Yulin, Guangxi, China.

\section{Received: 11 December 2017 Accepted: 30 July 2018}

\section{Published online: 06 August 2018}

\section{References}

1. Jung C, Pillen K, Staiger D, Coupland G, von Korff M. Recent advances in flowering time control. Front Plant Sci. 2017;7:2011.

2. Abe M, Kobayashi $Y$, Yamamoto S, Daimon $Y$, Yamaguchi A, Ikeda $Y$, Ichinoki H, Notaguchi M, Goto K, Araki T. FD, a bZIP protein mediating signals from the floral pathway integrator FT at the shoot apex. Science. 2005;309(5737): 1052-6.

3. Wigge PA, Kim MC, Jaeger KE, Busch W, Schmid M, Lohmann JU, Weigel D. Integration of spatial and temporal information during floral induction in Arabidopsis. Science. 2005;309(5737):1056-9.

4. Kojima S, Takahashi Y, Kobayashi Y, Monna L, Sasaki T, Araki T, Yano M. $\mathrm{Hd} 3 \mathrm{a}$, a rice ortholog of the Arabidopsis FT gene, promotes transition to flowering downstream of $\mathrm{Hd} 1$ under short-day conditions. Plant Cell Physiol. 2002;43(10):1096-105.

5. Yano M, Katayose Y, Ashikari M, Yamanouchi U, Monna L, Fuse T, Baba T, Yamamoto K, Umehara Y, Nagamura Y. Hd1, a major photoperiod sensitivity quantitative trait locus in rice, is closely related to the Arabidopsis flowering time gene CONSTANS. Plant Cell. 2000;12(12):2473-83.

6. Cao K, Cui L, Zhou X, Ye L, Zou Z, Deng S. Four tomato FLOWERING LOCUS T-like proteins act antagonistically to regulate floral initiation. Front Plant Sci. 2015;6
7. Hsu C-Y, Adams JP, Kim H, No K, Ma C, Strauss SH, Drnevich J, Vandervelde $L$, Ellis JD, Rice BM. FLOWERING LOCUS T duplication coordinates reproductive and vegetative growth in perennial poplar. Proc Natl Acad Sci. 2011;108(26):10756-61.

8. Hsu C-Y, Liu Y, Luthe DS, Yuceer C. Poplar FT2 shortens the juvenile phase and promotes seasonal flowering. Plant Cell. 2006;18(8):1846-61.

9. Tränkner C, Lehmann S, Hoenicka H, Hanke M-V, Fladung M, Lenhardt D, Dunemann F, Gau A, Schlangen K, Malnoy M. Over-expression of an FThomologous gene of apple induces early flowering in annual and perennial plants. Planta. 2010;232(6):1309-24.

10. Pin PA, Benlloch R, Bonnet D, Wremerth-Weich E, Kraft T, Gielen JJ, Nilsson O. An antagonistic pair of FT homologs mediates the control of flowering time in sugar beet. Science. 2010;330(6009):1397-400.

11. Lin M-K, Belanger H, Lee Y-J, Varkonyi-Gasic E, Taoka K-I, Miura E, Xoconostle-Cázares B, Gendler K, Jorgensen RA, Phinney B. FLOWERING LOCUS T protein may act as the long-distance florigenic signal in the cucurbits. Plant Cell. 2007:19(5):1488-506.

12. Blackman BK, Strasburg JL, Raduski AR, Michaels SD, Rieseberg LH. The role of recently derived FT paralogs in sunflower domestication. Curr Biol. 2010; 20(7):629-35.

13. Hecht V, Laurie RE, Vander Schoor JK, Ridge S, Knowles CL, Liew LC, Sussmilch FC, Murfet IC, Macknight RC, Weller JL. The pea GIGAS gene is a FLOWERING LOCUS T homolog necessary for graft-transmissible specification of flowering but not for responsiveness to photoperiod. Plant Cell. 2011;23(1):147-61.

14. Kong F, Liu B, Xia Z, Sato S, Kim BM, Watanabe S, Yamada T, Tabata S, Kanazawa A, Harada K. Two coordinately regulated homologs of FLOWERING LOCUS T are involved in the control of photoperiodic flowering in soybean. Plant Physiol. 2010;154(3):1220-31.

15. Navarro C, Abelenda JA, Cruz-Oró E, Cuéllar CA, Tamaki S, Silva J, Shimamoto K, Prat S. Control of flowering and storage organ formation in potato by FLOWERING LOCUS T. Nature. 2011;478(7367):119-22.

16. Tamaki S, Tsuji H, Matsumoto A, Fujita A, Shimatazi Z, Terada R, Sakamoto T, Shimamotao K. FT-like proteins induce transposon silencing in the shoot apex during floral induction in rice. PNAS. 2015;112(8):901-10.

17. Halliwell J, Borrill P, Gordon A, Kowalczyk R, Pagano ML, Saccomanno B, Bentley AR, Uauy C, Cockram J. Systematic Investigation of FLOWERING LOCUS T-Like Poaceae Gene Families Identifies the Short-Day Expressed Flowering Pathway Gene, TaFT3 in Wheat (Triticum aestivum L.). Front Plant Sci. 2016;7(857)

18. Meng X, Muszynski MG, Danilevskaya ON. The FT-like ZCN8 gene functions as a floral activator and is involved in photoperiod sensitivity in maize. Plant Cell. 2011;23(3):942-60.

19. Goto N, Kumagai T, Koornneef M. Flowering responses to light-breaks in photomorphogenic mutants of Arabidopsis thaliana, a long-day plant. Physiol Plant. 1991;83(2):209-15.

20. Ishikawa R, Tamaki S, Yokoi S, Inagaki N, Shinomura T, Takano M, Shimamoto K. Suppression of the floral activator Hd3a is the principal cause of the night break effect in rice. Plant Cell. 2005:17(12):3326-36.

21. Ishikawa R, Shinomura T, Takano M, Shimamoto K. Phytochrome dependent quantitative control of Hd3a transcription is the basis of the night break effect in rice flowering. Genes Genet Syst. 2009;84(2):179-84.

22. Hayama R, Agashe B, Luley E, King R, Coupland G. A circadian rhythm set by dusk determines the expression of $\mathrm{FT}$ homologs and the short-day photoperiodic flowering response in Pharbitis. Plant Cell. 2007;19(10):2988-3000.

23. Park YG, Muneer S, Soundararajan P, Manivnnan A, Jeong BR. Light quality during night interruption affects morphogenesis and flowering in geranlum. Hortic Environ Biotechnol. 2017:58(3):212-7.

24. Demotes-Mainard S, Péron T, Corot A, Bertheloot J, Le Gourrierec J, Pelleschi-Travier S, Crespel L, Morel P, Huché-Thélier L, Boumaza R. Plant responses to red and far-red lights, applications in horticulture. Environ Exp Bot. 2016;121:4-21.

25. Cerdán PD, Chory J. Regulation of flowering time by light quality. Nature. 2003:423(6942):881-5.

26. Kim SY, YU X, Michaels SD. Regulation of CONSTANS and FLOWERING LOCUS T expression in response to changing light quality. Plant Physiol. 2008;148(1):269-79.

27. Kong SG, Okajima K. Diverse photoreceptors and light responses in plants. J Plant Res. 2016;129(2):111-4.

28. Carvalho RF, Takaki M, Azevedo RA. Plant pigments: the many faces of light perception. Acta Physiol Plant. 2011;33(2):241-8. 
29. Ádám É, Hussong A, Bindics J, Wüst F, Viczián A, Essing M, Medzihradszky M, Kircher S, Schäfer E, Nagy F. Altered dark-and photoconversion of phytochrome B mediate extreme light sensitivity and loss of photoreversibility of the phyB-401 mutant. PLoS One. 2011;6(11):e27250.

30. Mockler TC, Guo H, Yang H, Duong H, Lin C. Antagonistic actions of Arabidopsis cryptochromes and phytochrome $\mathrm{B}$ in the regulation of floral induction. Development. 1999;126(10):2073-82.

31. Weller JL, Reid JB. Photoperiodism and photocontrol of stem elongation in two photomorphogenic mutants of Pisum sativum L. Planta. 1993;189(1): $15-23$.

32. Childs KL, Miller FR, Cordonnier-Pratt M-M, Pratt LH, Morgan PW, Mullet JE. The sorghum photoperiod sensitivity gene, Ma3, encodes a phytochrome B. Plant Physiol. 1997;113(2):611-9.

33. Izawa T, Oikawa T, Sugiyama N, Tanisaka T, Yano M, Shimamoto K. Phytochrome mediates the external light signal to repress FT orthologs in photoperiodic flowering of rice. Genes Dev. 2002;16(15):2006-20.

34. Endo M, Nakamura S, Araki T, Mochizuki N, Nagatani A. Phytochrome B in the mesophyll delays flowering by suppressing FLOWERING LOCUS T expression in Arabidopsis vascular bundles. Plant Cell. 2005;17(7):1941-52.

35. Hauser BA, Pratt LH, Cordonnier-Pratt M-M. Absolute quantification of five phytochrome transcripts in seedlings and mature plants of tomato (Solanum lycopersicum L.). Planta. 1997;201(3):379-87.

36. Soyk S, Müller NA, Park SJ, Schmalenbach I, Jiang K, Hayama R, Zhang L, Van Eck J, Jiménez-Gómez JM, Lippman ZB. Variation in the flowering gene SELF PRUNING 5G promotes day-neutrality and early yield in tomato. Nat Genet. 2017:49(1):162-8.

37. Thomas B, Vince-Prue D. Photoperiodism in plants. London: Academic Press; 1996.

38. Pierik R, de Wit M. Shade avoidance: phytochrome signalling and other aboveground neighbour detection cues. J Exp Bot. 2014;65(11):2815-24.

39. Yamada A, Tanigawa T, Suyama T, Matsuno T, Kunitake T. Night break treatment using different light sources promotes or delays growth and flowering of Eustoma grandiflorum (Raf.) Shinn. J Jpn Soc Horticultural Sci. 2008;77(1):69-74.

40. Craig DS, Runkle ES. An intermediate phytochrome photoequilibria from night-interruption lighting optimally promotes flowering of several long-day plants. Environ Exp Bot. 2016;121:132-8.

41. Lund JB, Blom TJ, Aaslyng JM. End-of-day lighting with different red/far-red ratios using light-emitting diodes affects plant growth of Chrysanthemumx morifolium Ramat.'coral charm'. HortScience. 2007;42(7):1609-11.

42. Runkle ES, Heins RD. Specific functions of red, far red, and blue light in flowering and stem extension of long-day plants. J Am Soc Hortic Sci. 2001; 126(3):275-82.

43. Zahedi SM, Sarikhani H. Effect of far-red light, temperature, and plant age on morphological changes and induction of flowering of a 'June-bearing' strawberry. Hortic Environ Biotechnol. 2016:57(4):340-7.

44. Ohtani T, Ishiguri Y. Inhibitory action of blue and far-red light in the flowering of Lemna paucicostata. Physiol Plant. 1979;47(4):255-9.

45. Yang ZQ, Li YX, Zhang JB, Zhang J, Zhu J, Gu LX, Zhang B. Effects of the red:far-red light ratio on photosynthetic characteristics of greenhouse cut Chrysanthemum - short communication. Hortic Sci. 2013;40(1):40-3.

46. Smith H. Physiological and ecological function within the phytochrome family. Annu Rev Plant Biol. 1995;46(1):289-315.

47. Franklin KA, Quail PH. Phytochrome functions in Arabidopsis development. J Exp Bot. 2010;61(1):11-24.

48. Zhao Y, Zhou J, Xing D. Phytochrome B-mediated activation of lipoxygenase modulates an excess red light-induced defence response in Arabidopsis. J Exp Bot. 2014;65(17):4907-18.

49. Cathey H, Borthwick H. Photoreversibility of floral initiation in chrysanthemum. Bot Gaz. 1957;119(2):71-6.

50. Downs R. Photoreversibility of flower initiation. Plant Physiol. 1956:31(4):279.

51. Valverde F, Mouradov A, Soppe W, Ravenscroft D, Samach A, Coupland G. Photoreceptor regulation of CONSTANS protein in photoperiodic flowering. Science. 2004;303(5660):1003-6.

52. Endo M, Tanigawa Y, Murakami T, Araki T, Nagatani A. PHYTOCHROMEDEPENDENT LATE-FLOWERING accelerates flowering through physical interactions with phytochrome B and CONSTANS. Proc Natl Acad Sci. 2013; 110(44):18017-22.

53. Karimi M, Inzé D, Depicker A. GATEWAYTM vectors for agrobacteriummediated plant transformation. Trends Plant Sci. 2002;7(5):193-5.

\section{Ready to submit your research? Choose BMC and benefit from}

- fast, convenient online submission

- thorough peer review by experienced researchers in your field

- rapid publication on acceptance

- support for research data, including large and complex data types

- gold Open Access which fosters wider collaboration and increased citations

- maximum visibility for your research: over $100 \mathrm{M}$ website views per year

At BMC, research is always in progress.

Learn more biomedcentral.com/submissions 